\title{
Synthesis and Properties of Novel Polyurethane-Imide Elastomers
}

\author{
Tomohiro Ueda, Shin-Ichi Inoue \\ Department of Applied Chemistry, Aichi Institute of Technology, Toyota, Japan \\ Email:w15801ww@aitech.ac.jp
}

How to cite this paper: Ueda, T. and Inoue, S.-I. (2018) Synthesis and Properties of Novel Polyurethane-Imide Elastomers. Open Journal of Organic Polymer Materials, 8, 1-13. https://doi.org/10.4236/ojopm.2018.81001

Received: November 1, 2017

Accepted: January 12, 2018

Published: January 15, 2018

Copyright $\odot 2018$ by authors and Scientific Research Publishing Inc. This work is licensed under the Creative Commons Attribution International License (CC BY 4.0).

http://creativecommons.org/licenses/by/4.0/

\begin{abstract}
Novel polyurethane-imide elastomers were prepared from isocyanates (hexamethylene, and 4,4'-dicyclohexyl diisocyanates), polytetramethylene glycol (PTMG1000, Mw = 1000), pyromellitic dianhydride, and 4,4'-diphenylmethane diamine. The formation of PUIEs was confirmed by Fourier transform infrared spectroscopy. The resultant films were studied through X-ray diffraction analysis, contact angle measurement, atomic force microscopy, solubility and swelling tests, tensile test, differential scanning calorimetry, dynamic mechanical analysis, and thermogravimetric analysis.
\end{abstract}

\section{Keywords}

Polyurethane-Imide Elastomer, Isocyanate, Morphology,

Mechanical and Thermal Properties

\section{Introduction}

Polyurethane elastomers (PUEs) having varying specifications, such as rubber elasticity, abrasion resistance, adhesion, are easily synthesized from isocyanates and polyols through the polyaddition reaction; this implies that PUEs have been widely used in a variety of applications and fields. However, in terms of heat-resistance, the PUEs that are formed from organic polymer materials have a basic problem. By improving this fundamental property, these elastomers may gain some industrial advantages; therefore, chemists have actively studied the heatresistance of PUEs. Consequently, the polyurethane-imide elastomer (PUIE) was prepared via an organic-organic hybrid between a urethane and an imide that had high-temperature stability, excellent electrical and mechanical properties, and good chemical resistance [1]-[15]. The PUIE possesses some properties distinct from other PUEs, such as heat and solvent resistances. Therefore, the PUIE 
materials have special applications in industry and continue to gain importance in a variety of applications that rely on heat and solvent resistances. The PUIEs are used in a surprising array of commercial applications and are classified into three major product types: foams [16] [17] [18], elastomers [19] [20] [21] [22], and resins [23] [24]. Our research interests lay in elastomers that are widely utilized for commercial products, and we have previously attempted to develop PUEs. Thus, we noted the lack of variety in the isocyanate raw materials currently used for PUIEs compared with the different isocyanates utilized in the field of polyurethanes. Therefore, to broaden the scope of potential applications, the use of different isocyanate and polyurethane units in PUIEs remains an important topic in polymer chemistry. It is important from both a fundamental and practical standpoint to study the synthesis of PUIEs and their properties.

In this article, the novel PUIEs were synthesized from isocyanates (hexamethylene diisocyanate (HDI) and 4,4'-dicyclohexyl diisocyanate $\left(\mathrm{H}_{12} \mathrm{MDI}\right)$ ), polytetramethylene glycol (PTMG, Mw: = 1000), pyromellitic dianhydride (PMDA), and 4,4'-diphenylmethane diamine (MDA). The morphology and the chemical and physical properties of these elastomers were studied.

\section{Experimental}

\subsection{Materials}

Hexamethylene, and 4,4'-dicyclohexyl diisocyanates and Polytetramethylene glycol were supplied by Tosoh Industry and were purified by distillation or dehydrated before use. Pyromellitic dianhydride, 4,4'-Diphenylmethane diamine, and dibutyltindilaurate were purchased from Tokyo Chemical Industry and were used without further purification. 1,4-Diazabicyclo[2.2.2] octane and N-Methyl-2pyrrolidone (NMP) were purchased from Nacalai Tesque, Inc. and NMP was purified by distillation.

\subsection{Synthesis}

The PUIEs were synthesized from the isocyanates (HDI and $\mathrm{H}_{12} \mathrm{MDI}$ ), PTMG1000, PMDA, and MDA via liquid polymerization (Scheme 1). Table 1 shows the recipe and imide content for each PUIE. The syntheses were performed as follows: 1) In a $100 \mathrm{~mL}$ four-necked separable reaction flask equipped with a mechanical stirrer, a gas inlet tube, and a reflux condenser were added PTMG1000 and DABCO, and the DABCO was dissolved completely at $100^{\circ} \mathrm{C}$. HDI and DBTL were added to the separable flask. The prepolymers were prepared by stirring at $100^{\circ} \mathrm{C}$ for $30 \mathrm{~min}$. Then, PMDA and NMP $(10 \mathrm{~mL})$ were added to the separable flask and stirred at $150^{\circ} \mathrm{C}$ for $15 \mathrm{~min}$. Finally, MDA and NMP $(30 \mathrm{~mL})$ were added to the separable flask and were stirred at $150^{\circ} \mathrm{C}$ for 4 h; 2) $\mathrm{H}_{12} \mathrm{MDI}$, PTMG1000, and DBTL were added to the separable flask. The prepolymers were prepared by stirring at $80^{\circ} \mathrm{C}$ for $30 \mathrm{~min}$. Then, PMDA and NMP $(10 \mathrm{~mL})$ were added to the separable flask and were stirred at $150^{\circ} \mathrm{C}$ for $15 \mathrm{~min}$ 

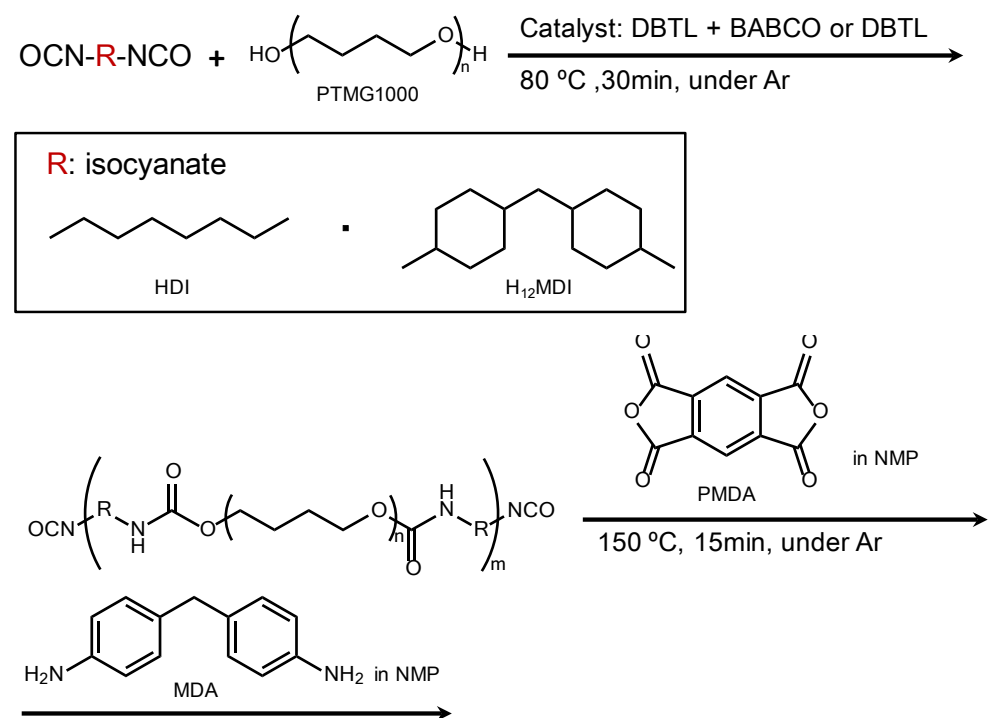

1) $150^{\circ} \mathrm{C}, 2 \mathrm{~h}$, under $\mathrm{Ar}$

2) $150^{\circ} \mathrm{C}, 24 \mathrm{~h}$,

3) $200^{\circ} \mathrm{C}, 4 \mathrm{~h}$, in vacuo

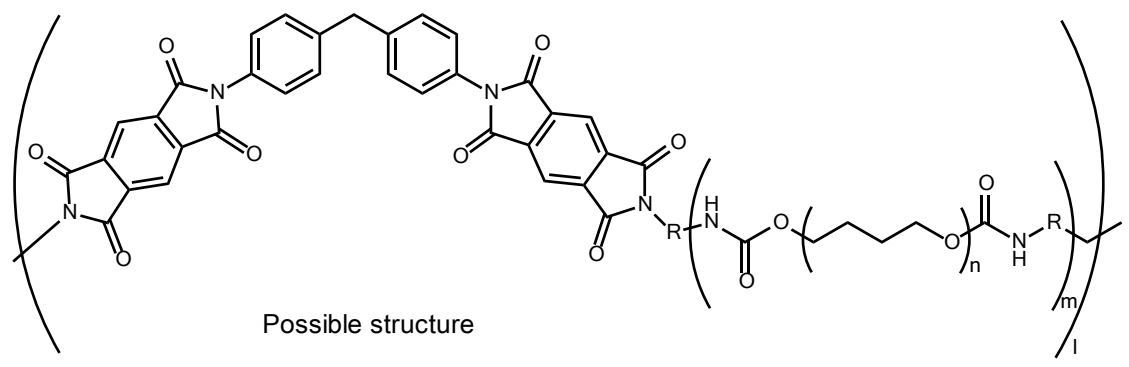

Scheme 1. Synthesis of polyurethane-imide elastomers (PUIEs) by the solution method.

Table 1. Synthesis of PUIEs.

\begin{tabular}{|c|c|c|c|c|c|c|c|}
\hline Sample & $\begin{array}{l}\text { Diisocyanate }^{\mathrm{a}} \\
\left(\times 10^{-3} \mathrm{~mol}\right)\end{array}$ & $\begin{array}{l}\text { PTMG1000 }^{\mathrm{b}} \\
\left(\times 10^{-3} \mathrm{~mol}\right)\end{array}$ & $\begin{array}{c}\mathrm{MDA}^{\mathrm{c}} \\
\left(\times 10^{-3} \mathrm{~mol}\right)\end{array}$ & $\begin{array}{c}\text { PMDA }^{\mathrm{d}} \\
\left(\times 10^{-3} \mathrm{~mol}\right)\end{array}$ & $\begin{array}{c}\mathrm{DBTL}^{\mathrm{e}} \\
\left(\times 10^{-5} \mathrm{~mol}\right)\end{array}$ & $\begin{array}{c}\mathrm{DABCO}^{\mathrm{f}} \\
\left(\times 10^{-5} \mathrm{~mol}\right)\end{array}$ & $\begin{array}{c}\text { Imide content } \\
(\mathrm{Wt} \%)\end{array}$ \\
\hline PUIE-HDI ${ }_{15}$ & 3.15 & 2.50 & 0.642 & 1.28 & 0.712 & 4.01 & 15 \\
\hline PUIE-HDI ${ }_{25}$ & 3.72 & 2.50 & 1.21 & 2.43 & 0.744 & 4.19 & 25 \\
\hline PUIE-HDI ${ }_{35}$ & 4.47 & 2.50 & 1.97 & 3.92 & 0.773 & 4.35 & 35 \\
\hline PUIE-HDI ${ }_{45}$ & 5.48 & 2.50 & 2.98 & 5.95 & 0.808 & 4.55 & 45 \\
\hline PUIE-HDI ${ }_{55}$ & 6.93 & 2.50 & 4.45 & 8.90 & 0.869 & 4.89 & 55 \\
\hline PUIE- $\mathrm{H}_{12} \mathrm{MDI}_{15}$ & 3.12 & 2.50 & 0.620 & 1.25 & 1.53 & - & 15 \\
\hline PUIE- $\mathrm{H}_{12} \mathrm{MDI}_{25}$ & 3.67 & 2.50 & 1.17 & 2.35 & 1.65 & - & 25 \\
\hline PUIE- $\mathrm{H}_{12} \mathrm{MDI}_{35}$ & 4.40 & 2.50 & 1.90 & 3.78 & 1.74 & - & 35 \\
\hline PUIE- ${ }_{12}$ MDI $_{45}$ & 5.38 & 2.50 & 2.88 & 5.75 & 1.85 & - & 45 \\
\hline PUIE- $\mathrm{H}_{12} \mathrm{MDI}_{55}$ & 6.80 & 2.50 & 4.30 & 8.60 & 2.04 & - & 55 \\
\hline
\end{tabular}

${ }^{\mathrm{a}} \mathrm{HDI}: \mathrm{Mw}=168.19, \mathrm{H}_{12} \mathrm{MDI}: \mathrm{Mw}=262.35$; ${ }^{\mathrm{b} T M G 1000:} \mathrm{Mw}=1000 ;{ }^{\mathrm{c}} \mathrm{MDA}: \mathrm{Mw}=200.24$; ${ }^{\mathrm{d}} \mathrm{PMDA}: \mathrm{Mw}=218.12 ;{ }^{\mathrm{e}} \mathrm{DBTL}: \mathrm{Mw}=631.56 ;{ }^{\mathrm{f}} \mathrm{DABCO} \mathrm{Mw}=$ 112.17; imide content is the theoretical value. 
besides MDA and NMP $(30 \mathrm{~mL})$ were also added to the separable flask and were stirred at $150^{\circ} \mathrm{C}$ for $2 \mathrm{~h}$. The degree of imide content was calculated using the following formula:

$$
\begin{aligned}
& \text { Imide content }(\mathrm{wt} \%)=\left(\text { imide }^{\mathrm{a}} /(\text { isocyanate }+ \text { PTMG }+ \text { MDA }+ \text { PMDA })\right) \times 100(1) \\
& \text { a: weight of isocyanate }{ }^{\mathrm{b}}+\mathrm{MDA}+\text { PMDA; } \\
& \text { b: (isocyanate }-\mathrm{PTMG}) \mathrm{mol} \times \text { isocyanate }(\mathrm{Mw}) .
\end{aligned}
$$

The resultant PUIE solutions were treated at $150^{\circ} \mathrm{C}$ for $24 \mathrm{~h}$ under the atmosphere using a centrifugal casting machine. The resultant films were heated at $200^{\circ} \mathrm{C}$ for $4 \mathrm{~h}$ under reduced pressure $(267-400 \mathrm{~Pa})$ to complete the imide reaction.

\subsection{Characterization}

\subsubsection{Fourier Transform Infrared (FTIR) Spectroscopy}

FTIR spectra were recorded on a JASCO FTIR-5300 spectrometer (Tokyo, Japan) equipped with an attenuated total reflection (ATR) system, which used an ATR500/M with an ATR prism KRS-5.

\subsubsection{X-Ray Diffraction (XRD) Analyses}

The XRD pattern was measured from $5^{\circ}$ to $35^{\circ}$ ( $2 \theta$ value) with $\mathrm{CuK} \alpha$ (conditions: $\lambda=0.154 \mathrm{~nm}, 40 \mathrm{kV}, 100 \mathrm{~mA}$ ) with a RINT $2500 \mathrm{~V} / \mathrm{PC}$ made by Rigaku (Tokyo, Japan).

\subsubsection{Morphological Analyses}

Contact angles (CA) were measured on dried films at room temperature $\left(23^{\circ} \mathrm{C} \pm\right.$ $2^{\circ} \mathrm{C}$ ) in the atmosphere using an Excimer (Yokohama, Japan) Image Standard 100. Samples were dripped of $5 \mu \mathrm{L}$.

Atomic force microscopy (AFM) measurements of the samples were carried out at room temperature and ambient pressure, using an OLYMPUS (Tokyo, Japan) NV2000. Most of the images were obtained in tapping mode (ACAFM) with a silicon nitride cantilever (OMMCL-AC 240TS-C2, Olympus optical).

\subsubsection{Chemical Properties}

Swelling tests were carried out using test pieces $(0.1000 \mathrm{~g})$ in benzene. They were put into benzene solution in test tube to keep $24 \mathrm{~h}$.

Solubility tests were carried out using test pieces $(0.1000 \mathrm{~g})$. Each test piece was soaked in a solvents (benzene, hexane, acetone, NMP, methanol, THF, DMF, or DMSO; $30 \mathrm{~mL}$ ) at room temperature for $24 \mathrm{~h}$.

\subsubsection{Mechanical Properties}

Hardness was measured on a KOBUNSHI KEIKI Asker durometer (Kyoto, Japan) using scale-A. The test procedure follows the JIS K 6253 standard.

Stress-strain measurements were performed on dumbbell-shopped samples cut from the PUIE films obtained (JIS K 6251-3 standard). The tests were performed at room temperature using an ORIENTEC RTC-1225A Universal Ten- 
sile Testing Instrument (Tokyo, Japan) equipped with a U-4300 extensometer. The crosshead speed used was $100 \mathrm{~mm} / \mathrm{min}$.

\subsubsection{Thermal Properties}

A Rigaku Thermo-Plus DSC-8230 instrument (Tokyo, Japan) was used for thermal analysis and operated at a heating rate of $10^{\circ} \mathrm{C} / \mathrm{min}$. The thermal transition behavior was studied over a temperature range of $-120^{\circ} \mathrm{C}$ to $200^{\circ} \mathrm{C}$ under an Ar atmosphere. Tests were conducted on samples of $5 \mathrm{mg}$ that the glass transition temperature $(\mathrm{Tg})$

Dynamic mechanical analyses (DMA) were performed on a Seiko Instruments DMS 6100 (Chiba, Japan) at a heating rate of $5^{\circ} \mathrm{C} / \mathrm{min}$ over the range of $-100^{\circ} \mathrm{C}$ to $300^{\circ} \mathrm{C}$ and at $20 \mathrm{~Hz}$ under an $\mathrm{N}_{2}$ atmosphere.

The thermal stability of PUIEs was tested under an $\mathrm{N}_{2}$ atmosphere through thermogravimetric analysis (TGA) using a Seiko Instruments TG/DTA6200 (Chiba, Japan) at a heating rate of $10^{\circ} \mathrm{C} / \mathrm{min}$ from $30^{\circ} \mathrm{C}$ to $500^{\circ} \mathrm{C}$.

\section{Results and Discussion}

\subsection{Fourier Transform Infrared (FTIR) Spectroscopy}

To examined the existence of the imide content in the PUIEs, FTIR spectral measurements were carried out. Figure 1 shows Carbonyl $\mathrm{C}=\mathrm{O}$ group absorptions. Three peaks were observed at around1700, 1720, and $1780 \mathrm{~cm}^{-1}$, which correspond to the hydrogen-bonded carbonyl stretching $v\left(\mathrm{C}=\mathrm{O}_{\text {bonded }}\right)$, the free carbonyl $\vee\left(\mathrm{C}=\mathrm{O}_{\text {free }}\right)$, and the imide carbonyl $\vee\left(\mathrm{C}=\mathrm{O}_{\text {imide }}\right)$, respectively. The peak-strength of the imide carbonyl group increased as the imide content increased.

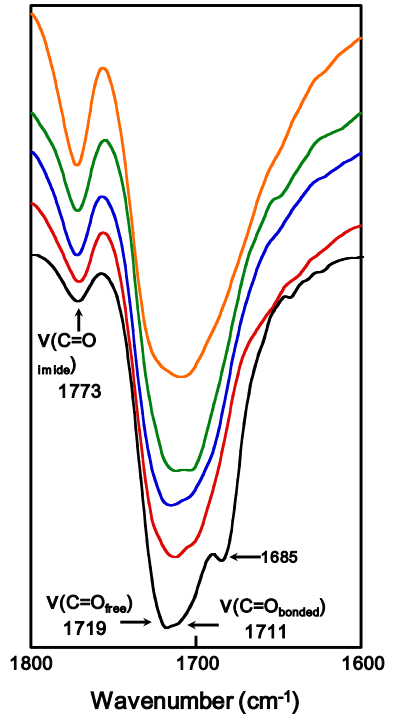

(A)

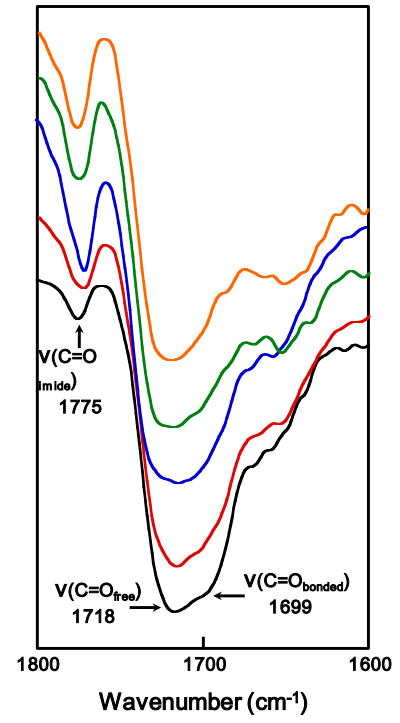

(B)

Figure 1. Fourier transform infrared (FTIR) spectra of PUIEs: (A) PUIE-HDI; and (B) PUIE- $\mathrm{H}_{12}$ MDI. Imide content: black $=15 \mathrm{wt} \%$, red $=25 \mathrm{wt} \%$, blue $=35 \mathrm{wt} \%$, green $=45$ $\mathrm{wt} \%$, and orange $=55 \mathrm{wt} \%$. 


\subsection{X-Ray Diffraction Analyses}

Figure 2 illustrates the XRD patterns of the PUIEs composed of the isocyanates. Broad diffraction peaks that were mainly attributed to the amorphous nature of these PUIEs are observed at around $2 \theta=6,17.5$ and 20 .

\subsection{Morphological Analyses}

Generally speaking, molecular angles are smaller for smooth surfaces than for the rough surfaces. In order to understand the distinction between the PUIEs with the isocyanates, it was necessary to observe and investigate the surface wettability of the films. The contact angles to water were measured at room temperature and atmospheric pressure on the surfaces of films. Table 2 and Figure 3 show the contact angles of the PUIE films with the isocyanates, HDI and $\mathrm{H}_{12} \mathrm{MDI}$. The values of the contact angles for the PUIE films were nearly identical, showing similar hydrophobicities among the films. However, although the values for the contact angles of the PUIE-HDI films were nearly identical as the imide content increased, the values for the contact angles of the PUIE- $\mathrm{H}_{12} \mathrm{MDI}$ films decreased as the imide content increased, showing that the hydrophobicity of these PUIE films gradually decreases.

The surface topographies of the PUIEs were examined by AFM (Figure 4), and phase-segregated morphologies of the PUIEs with various hard segment

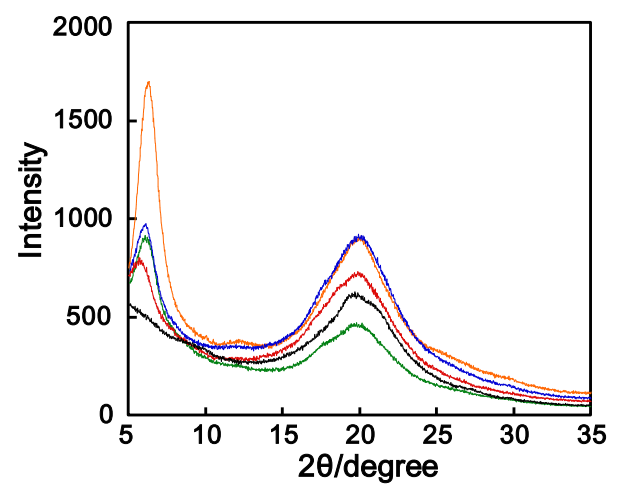

(A)

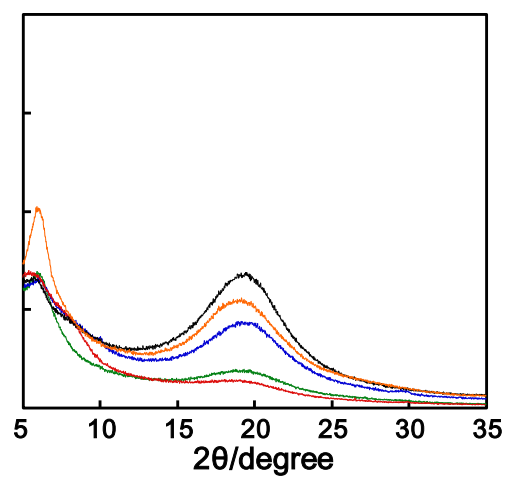

(B)

Figure 2. X-ray diffraction (XRD) patterns of PUIEs: (A) PUIE-HDI and (B) PUIE- ${ }_{12}$ MDI. Imide content: black $=15 \mathrm{wt} \%$, red $=25 \mathrm{wt} \%$, blue $=35 \mathrm{wt} \%$, green $=45 \mathrm{wt} \%$, and orange $=55 \mathrm{wt} \%$.

Table 2. Contact angle micrographs of a water droplet on PUIEs with various isocyanates.

\begin{tabular}{cccc}
\hline Sample & $\theta(\mathrm{deg})$ & & $\theta(\mathrm{deg})$ \\
\hline PUIE-HDI $_{15}$ & 106.1 & PUIE- $_{12} \mathrm{MDI}_{15}$ & 109.8 \\
PUIE-HDI $_{25}$ & 108.2 & PUIE-H $_{12} \mathrm{MDI}_{25}$ & 105.1 \\
PUIE-HDI $_{35}$ & 108.7 & PUIE- $_{12} \mathrm{MDI}_{35}$ & 103.7 \\
PUIE-HDI $_{45}$ & 105.4 & PUIE- $_{12} \mathrm{MDI}_{45}$ & 88.1 \\
PUIE-HDI $_{55}$ & 106.5 & PUIE- $_{12} \mathrm{MDI}_{55}$ & 76.4 \\
\hline
\end{tabular}




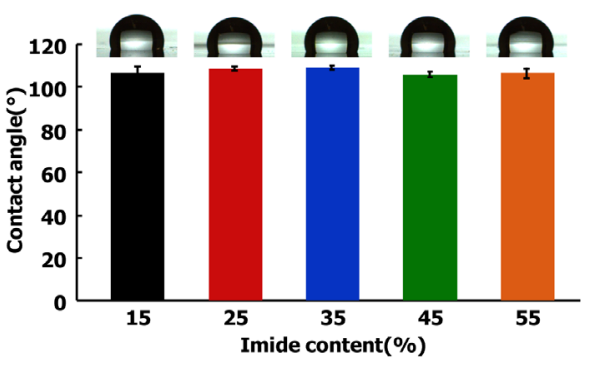

(A)

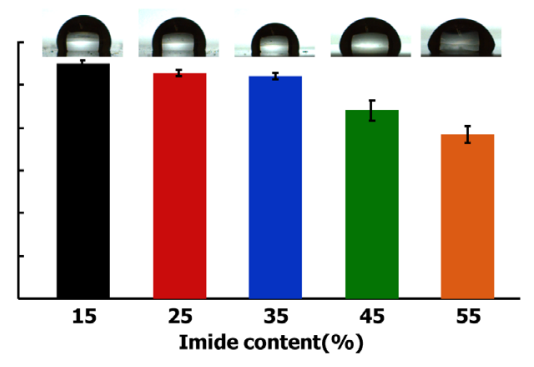

(B)

Figure 3. Contact angle micrographs of a water droplet on PUIEs: (A) PUIE-HDI and (B) PUIE- $\mathrm{H}_{12}$ MDI. Imide content: black $=15 \mathrm{wt} \%$, red $=25 \mathrm{wt} \%$, blue $=35 \mathrm{wt} \%$, green $=45$ $\mathrm{wt} \%$, and orange $=55 \mathrm{wt} \%$.
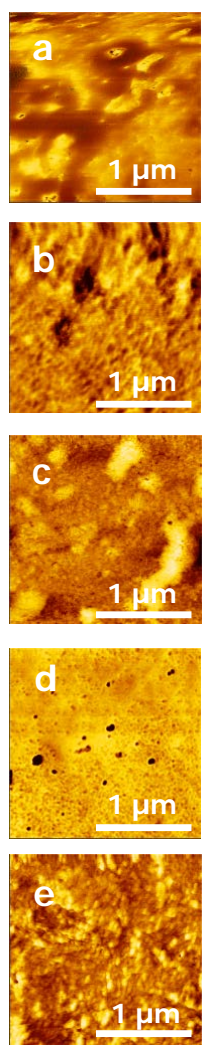

(A)
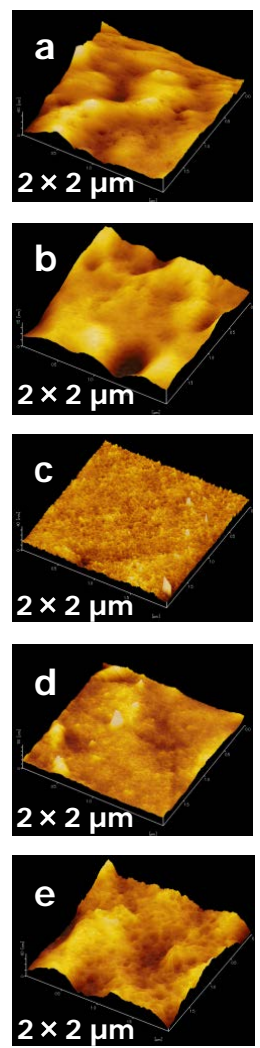

(A)
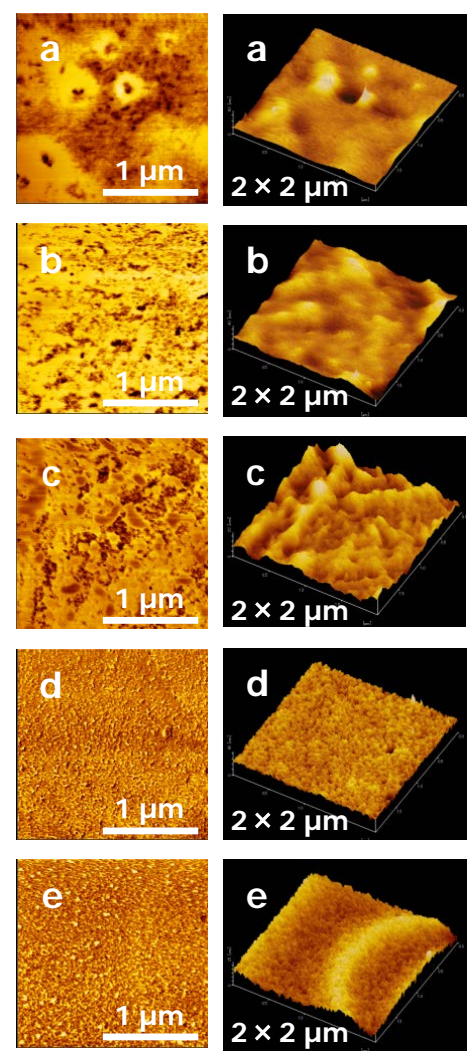

(B)

Figure 4. Topographic AFM images of PUIEs: (A) PUIE-HDI and (B) PUIE- $\mathrm{H}_{12}$ MDI. Imide content: $\mathrm{a}=15 \mathrm{wt} \%, \mathrm{~b}=25 \mathrm{wt} \%, \mathrm{c}=35 \mathrm{wt} \%, \mathrm{~d}=45 \mathrm{wt} \%$, and $\mathrm{e}=55 \mathrm{wt} \%$.

structures were observed. The topographical heterogeneity was studied from the images. In these images, dark and bright regions are appeared as the urethane and imide contents and other content, respectively. Changes were observed in the surface morphology as the imide content increased. Dark-colored spots which are urethane and imide contents were dispersed all over the matrix parts. Inclusions of the urethane and imide contents could be seen in some limited areas. Comparing the two kinds of films, the AFM images of PUIE-HDI and PUIE- $\mathrm{H}_{12}$ MDI revealed a rough smooth surface. 


\subsection{Chemical Properties}

The solvent resistances of the PUIEs (PUIE- $\mathrm{HDI}_{15-55}$ and PUIE- $\mathrm{H}_{12} \mathrm{MDI}_{15-55}$ ) were tested by immersing each PUIE films in various solvents, including benzene, hexane, acetone, THF, NMP, methanol, DMF, and DMSO. The results are presented in Table 3. All of the PUIEs were resistant to hexane at room temperature. The PUIE-HDIs were resistant to DMSO at room temperature. However, no PUIE- $\mathrm{H}_{12} \mathrm{MDIs}$ were resistant to NMP at room temperature. Generally speaking, the PUIE films show good solvent resistance. The reason for this is considered to be the uniformity caused by the formation of networked structures between the imide and the urethane.

Swelling tests were then performed using the PUIEs. As evident from Table 4, each of the swelling rates of the PUIE-HDIs decreased as the imide content

Table 3. Solubility of PUIEs with various isocyanates. ${ }^{\text {a }}$

\begin{tabular}{|c|c|c|c|c|c|c|c|c|}
\hline Sample & Benzene & Hexane & Acetone & THF & NMP & Methanol & DMF & DMSO \\
\hline PUIE-HDI ${ }_{15}$ & $\triangle$ & $x$ & $\triangle$ & $\triangle$ & O & $\triangle$ & $\triangle$ & $x$ \\
\hline PUIE-HDI ${ }_{25}$ & $\triangle$ & $x$ & $\triangle$ & $\triangle$ & $\triangle$ & $\times$ & $\triangle$ & $x$ \\
\hline PUIE-HDI $_{35}$ & $x$ & $\times$ & $\times$ & $\triangle$ & $\triangle$ & $\times$ & $\triangle$ & $x$ \\
\hline PUIE-HDI ${ }_{45}$ & $x$ & $x$ & $x$ & $x$ & $x$ & $x$ & $x$ & $x$ \\
\hline PUIE-HDI $_{55}$ & $x$ & $\times$ & $x$ & $\times$ & $\times$ & $x$ & $\times$ & $x$ \\
\hline PUIE- $\mathrm{H}_{12} \mathrm{MDI}_{15}$ & $\triangle$ & $x$ & $\triangle$ & $\triangle$ & O & $x$ & $\triangle$ & $x$ \\
\hline PUIE- $\mathrm{H}_{12} \mathrm{MDI}_{25}$ & $\triangle$ & $x$ & $\triangle$ & O & O & $\triangle$ & O & $\triangle$ \\
\hline PUIE- $\mathrm{H}_{12} \mathrm{MDI}_{35}$ & $x$ & $\times$ & $x$ & O & O & $\triangle$ & $\triangle$ & $\triangle$ \\
\hline PUIE- $\mathrm{H}_{12} \mathrm{MDI}_{45}$ & $x$ & $x$ & $x$ & O & O & $x$ & O & $\triangle$ \\
\hline PUIE- $\mathrm{H}_{12} \mathrm{MDI}_{55}$ & $x$ & $x$ & $x$ & $\times$ & O & $x$ & $\times$ & $\triangle$ \\
\hline
\end{tabular}

O: completely dissolved, $\triangle$ : slightly dissolved, $\times$ : undissolved. ${ }^{a}$ Measurement conditions: benzene, hexane, acetone, THF, NMP, methanol, DMF or DMSO as the solvent at room temperature $\left(23^{\circ} \mathrm{C} \pm 2{ }^{\circ} \mathrm{C}\right)$.

Table 4. Physical properties of PUIEs with various isocyanates.

\begin{tabular}{|c|c|c|c|c|c|}
\hline Sample & $\begin{array}{l}\text { Hardness }^{\mathrm{a}} \\
\text { (Shore A) }\end{array}$ & $\begin{array}{c}\text { Swelling rate } \\
(\%)\end{array}$ & $\begin{array}{l}T g^{\mathrm{c}} \\
\left({ }^{\circ} \mathrm{C}\right)\end{array}$ & $\begin{array}{l}\mathrm{T}_{5}^{\mathrm{d}} \\
\left({ }^{\circ} \mathrm{C}\right)\end{array}$ & $\begin{array}{l}\mathrm{T}_{50}{ }^{\mathrm{d}} \\
\left({ }^{\circ} \mathrm{C}\right)\end{array}$ \\
\hline PUIE-HDI ${ }_{15}$ & 46 & 387 & -70.8 & 322 & 421 \\
\hline PUIE-HDI $_{25}$ & 65 & 296 & -68.8 & 326 & 423 \\
\hline PUIE-HDI ${ }_{35}$ & 73 & 222 & -68.0 & 331 & 431 \\
\hline PUIE-HDI $_{45}$ & 82 & 168 & -68.3 & 338 & 438 \\
\hline PUIE-HDI $_{55}$ & 89 & 148 & -68.5 & 340 & 461 \\
\hline PUIE- $\mathrm{H}_{12} \mathrm{MDI}_{15}$ & 45 & 705 & -33.7 & 317 & 425 \\
\hline PUIE- $\mathrm{H}_{12} \mathrm{MDI}_{25}$ & 65 & 331 & -30.1 & 311 & 429 \\
\hline PUIE- $\mathrm{H}_{12} \mathrm{MDI}_{35}$ & 76 & 370 & -32.5 & 317 & 437 \\
\hline PUIE- $\mathrm{H}_{12} \mathrm{MDI}_{45}$ & 84 & 300 & -38.7 & 310 & 445 \\
\hline PUIE- $\mathrm{H}_{12} \mathrm{MDI}_{55}$ & 92 & 310 & -46.3 & 328 & 461 \\
\hline
\end{tabular}

${ }^{\mathrm{a}}$ Measurement conditions: shore A type, total thickness $=6 \mathrm{~mm}$, room temperature $\left(23^{\circ} \mathrm{C} \pm 2{ }^{\circ} \mathrm{C}\right){ }^{\mathrm{b}} \mathrm{Mea}$ surement condition: benzene solvent at room temperature $\left(23^{\circ} \mathrm{C} \pm 2^{\circ} \mathrm{C}\right)$ for $24 \mathrm{~h}$. ${ }^{\circ}$ Differential scanning calorimetry was performed at heating rate of $10^{\circ} \mathrm{C} / \mathrm{min}$ from $-100^{\circ} \mathrm{C}$ to $300^{\circ} \mathrm{C}$ under an $\mathrm{Ar}$ atmosphere. ${ }^{\mathrm{d}}$ Thermogravimetric analysis was performed at a heating rate of $10^{\circ} \mathrm{C} / \mathrm{min}$ from $30^{\circ} \mathrm{C}$ to $500^{\circ} \mathrm{C}$ under an $\mathrm{Ar}$ atmosphere. 
increased, demonstrating the increase in crosslinking density. However, the swelling rates of the PUIE- $\mathrm{H}_{12}$ MDIs were unsteady. Additionally, the swelling rate increased in the following order based on the type of isocyanate: PUIE- $\mathrm{H}_{12}$ MDI > PUIE-MDI. This difference is considered to be due to the structure of the isocyanate.

\subsection{Mechanical Properties}

Table 4 shows the hardness. The hardness of the PUIE-HDIs and PUE- $\mathrm{H}_{12} \mathrm{MDIs}$ are almost same and increased as imide content increased. This is due to the molecular chains of the PUIEs with the isocyanates (HDI and $\mathrm{H}_{12} \mathrm{MDI}$ ), which are similar to the mobility of the molecular chains.

Figure 5 shows stress-strain curves of the PUIEs. Table 5 shows the tensile strength and elongation at the breaking point. Comparing the tensile strength and elongation at the breaking point of the PUIEs, it can be seen that each of the tensile strength values are almost the same and that the values for the elongation at the breaking point follow this order for the isocyanates: PUIE-HDI > PUIE$\mathrm{H}_{12}$ MDI. Also, the tensile strength increased with increasing imide content, and the elongation at the breaking point decreased with increasing imide content. This is caused mainly by the ratio of imide content, and it suggests both that the network chain density in the composite increases with increasing imide content and that cross-linking occurs between the imide contents. It is important to mention that the PUIEs almost lose their elasticity, especially, with high imide content. Therefore, the ratio of urethane content and imide content need to be controlled in synthesis of PUIEs.

Table 5. Tensile properties of PUIEs with various isocyanates.

\begin{tabular}{|c|c|c|c|c|c|c|c|c|c|}
\hline Sample ${ }^{\mathrm{a}}$ & $\begin{array}{c}\sigma 10 \\
(\mathrm{MPa})\end{array}$ & $\begin{array}{c}\sigma 50 \\
(\mathrm{MPa})\end{array}$ & $\begin{array}{c}\sigma 100 \\
(\mathrm{MPa})\end{array}$ & $\begin{array}{c}\sigma 200 \\
(\mathrm{MPa})\end{array}$ & $\begin{array}{c}\sigma 300 \\
(\mathrm{MPa})\end{array}$ & $\begin{array}{c}\sigma 400 \\
(\mathrm{MPa})\end{array}$ & $\begin{array}{c}\sigma 500 \\
(\mathrm{MPa})\end{array}$ & $\begin{array}{c}\sigma^{\mathrm{b}} \\
(\mathrm{MPa})\end{array}$ & $\begin{array}{l}E b^{c} \\
(\%)\end{array}$ \\
\hline PUIE-HDI $_{15}$ & 1.27 & 2.59 & 3.20 & 5.72 & 9.95 & 15.2 & 23.1 & 35.0 & 624 \\
\hline PUIE-HDI ${ }_{25}$ & 1.60 & 3.58 & 4.88 & 7.81 & 11.9 & 18.4 & 29.2 & 42.9 & 587 \\
\hline PUIE-HDI $_{35}$ & 2.83 & 5.42 & 6.81 & 9.69 & 13.7 & 19.4 & 28.4 & 46.5 & 643 \\
\hline PUIE-HDI ${ }_{45}$ & 6.02 & 9.73 & 11.4 & 15.4 & 22.8 & 36.5 & - & 55.2 & 492 \\
\hline PUIE-HDI ${ }_{55}$ & 13.2 & 15.8 & 17.4 & 24.2 & 38.9 & 64.4 & - & 68.4 & 413 \\
\hline PUIE-H $_{12}$ MDI $_{15}$ & 0.842 & 1.70 & 2.17 & 2.85 & 5.11 & 10.5 & - & 12.7 & 460 \\
\hline PUIE- $\mathrm{H}_{12} \mathrm{MDI}_{25}$ & 1.81 & 3.84 & 5.16 & 9.02 & 17.6 & 32.5 & - & 46.7 & 479 \\
\hline PUIE-H $_{12}$ MDI $_{35}$ & 5.22 & 9.51 & 13.9 & 29.4 & 55.1 & - & - & 76.8 & 362 \\
\hline PUIE-H $_{12}$ MDI $_{45}$ & 15.9 & 20.8 & 26.6 & 42.6 & - & - & - & 49.5 & 242 \\
\hline PUIE-H ${ }_{12} \mathrm{MDI}_{55}$ & 28.3 & 32.5 & 38.3 & 55.1 & - & - & - & 62.4 & 253 \\
\hline
\end{tabular}

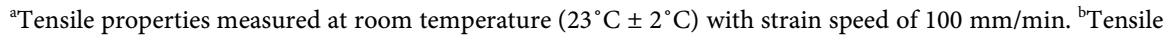
strength at breaking point. ${ }^{\circ}$ Elongation at breaking point. 


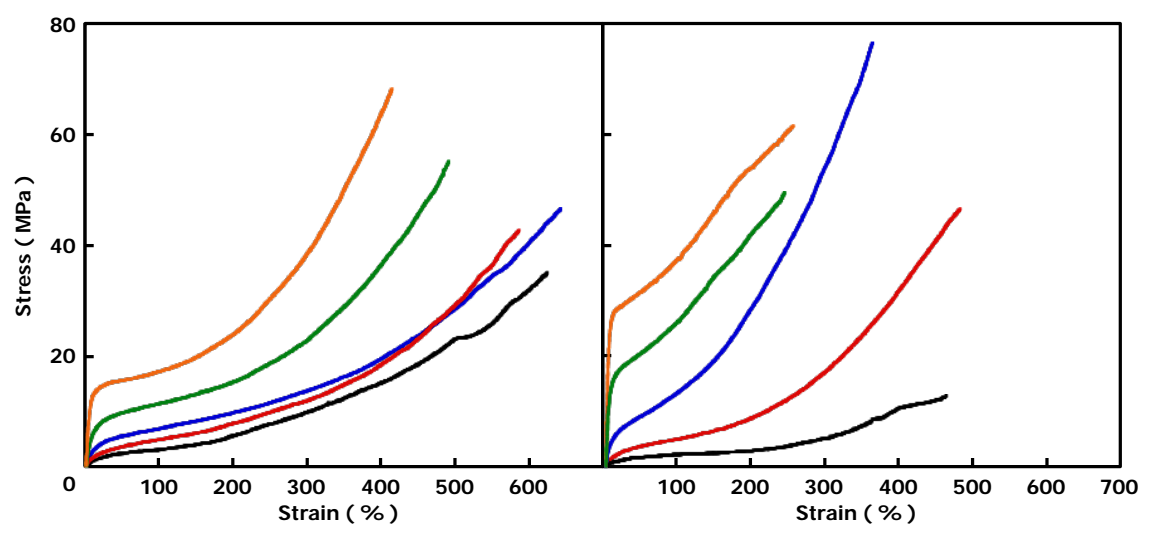

(A)

(B)

Figure 5. Stress-strain curves of PUIEs: (A) PUIE-HDI and (B) PUIE- ${ }_{12}$ MDI. Imide content: black $=15 \mathrm{wt} \%$, red $=25 \mathrm{wt} \%$, blue $=35 \mathrm{wt} \%$, green $=45 \mathrm{wt} \%$, and orange $=55$ wt $\%$.

\subsection{Thermal Properties}

Table 4 reports the $\mathrm{Tg}$ values of the PUIEs. The $\mathrm{Tg}$ s of the PUIE-HDIs were nearly identical as the imide content increased. However, PUIE- $\mathrm{H}_{12}$ MDIs fell as the imide content increased. The chemical structure and crosslinking density of PUIE influence to the Tgs of PUIEs. The Tgs of PUIEs fell as the imide content or the number of crosslink increased. Moreover, when the steric hindrance caused by the formation of physical and chemical crosslinks between molecular chains, probably the Tgs of PUIEs fell.

Figure 6 shows the viscoelastic behavior of the PUIEs through the storage modulus (E') and $\tan \delta\left(\tan \delta=\mathrm{E}^{\prime \prime} / \mathrm{E}^{\prime}\right)$. None of the PUIEs had a rubbery plateau. These results suggest that the PUIEs have much more crosslinking structure, but their molecular chains can still move easily above the $\mathrm{Tg}$. Additionally, the thermal properties of the PUIEs increased with increasing imide content.

Table 4 shows the TGA curves of the PUIEs. All of the PUIEs were thermally stable up to around $300^{\circ} \mathrm{C}$ and began to lose weight at a higher temperature. The $5 \%$ weight loss temperature $\left(\mathrm{T}_{5}\right)$ of the PUIEs changed according to the following isocyanate order: PUIE-HDI $>$ PUIE- $\mathrm{H}_{12} \mathrm{MDI}$. The $50 \%$ weight loss temperatures $\left(\mathrm{T}_{50}\right)$ of the PUE-HDI and PUIE- $\mathrm{H}_{12}$ MDI were identical. In general, the decomposition of PUIE is believed to take place in two main steps: the urethane linkage first dissociates to the isocyanate and alcohol at $300^{\circ} \mathrm{C}-350^{\circ} \mathrm{C}$, followed by imide degradation at temperatures above $400^{\circ} \mathrm{C}$. From these results, it is obvious that the PUIEs with higher imide content are more thermally stable. Also, the weight loss temperatures increased according to the following isocyanate order: PUIE- $\mathrm{H}_{12} \mathrm{MDI}>$ PUIE-HDI, and the $\mathrm{T}_{5} \mathrm{~s}$ and $\mathrm{T}_{50} \mathrm{~s}$ of the PUIEs increased as the imide content increased.

\section{Conclusion}

Novel PUIEs were synthesized from different isocyanates (HDI and $\mathrm{H}_{12} \mathrm{MDI}$ ), 


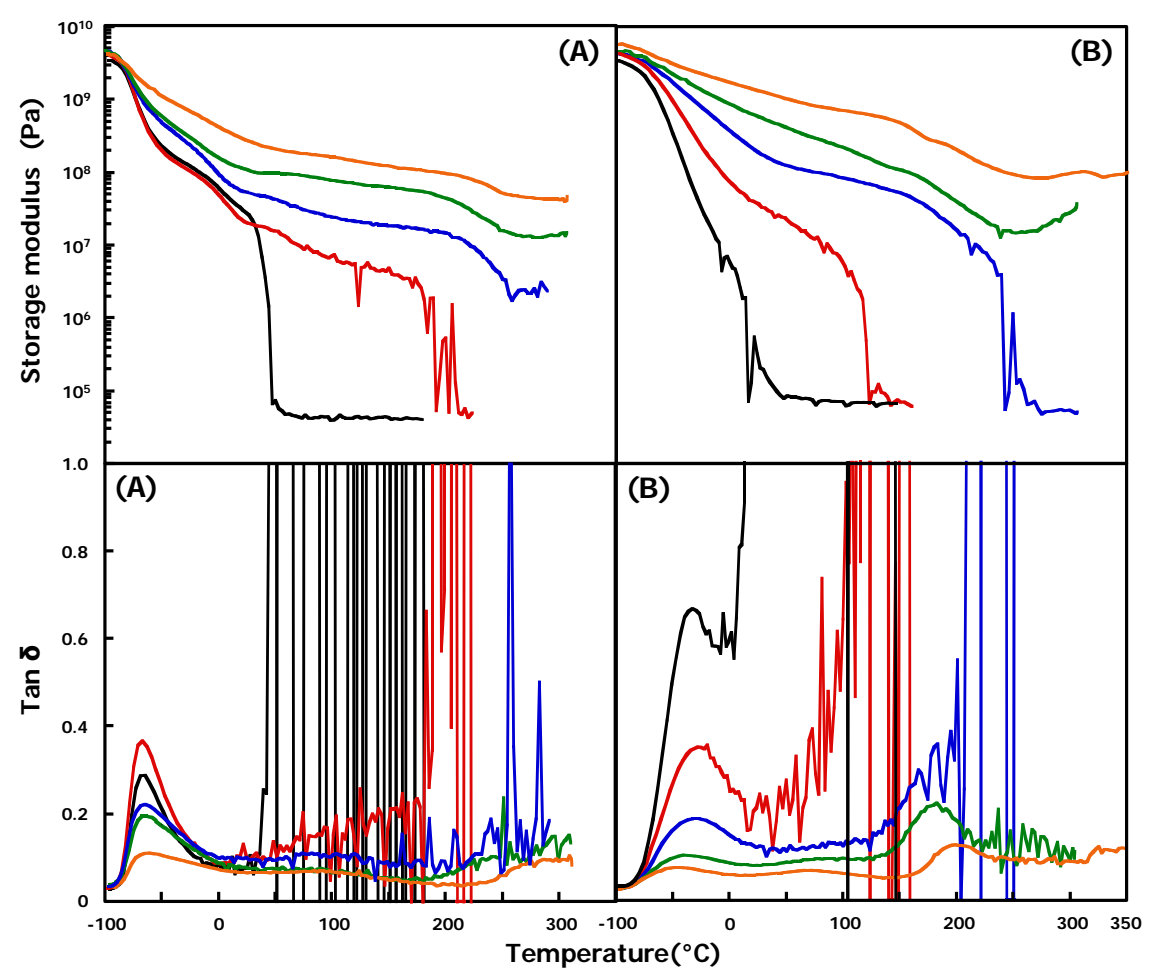

Figure 6. Storage modules and $\tan \delta$-temperature of PUIEs: (A) PUIE-HDI and (B) PUIE- $\mathrm{H}_{12}$ MDI. Imide content: black $=15 \mathrm{wt} \%$, red $=25 \mathrm{wt} \%$, blue $=35 \mathrm{wt} \%$, green $=45$ $\mathrm{wt} \%$, and orange $=55 \mathrm{wt} \%$.

and these isocyanates affected the properties of the resultant PUIEs to a significant extent. An isocyanate with a comparatively regular molecular chain, such as HDI, resulted in PUIEs with acceptable properties. By contrast, the use of isocyanate with low chain regularity, such as $\mathrm{H}_{12} \mathrm{MDI}$, led to PUIEs with poor elasticity. The PUIEs that were crosslinked from isocyanates with low regularity were harder and firmer.

\section{Acknowledgements}

The authors are grateful to the ceramic laboratory of AIT for providing access to the X-ray instruments and to Mr. Tomohiro Nishio for performing the dynamic mechanical analysis.

\section{References}

[1] Jeno, J.-Y. and Tak, T.-M. (1996) Synthesis and Characterization of Block Copoly(Urethane-Imide). Journal of Applied Polymer Science, 62, 763-769.

https://doi.org/10.1002/(SICI)1097-4628(19961031)62:5<763::AID-APP7>3.0.CO;2$\underline{\mathrm{U}}$

[2] Zuo, M. and Takeichi, T. (1997) Novel Method for the Preparation of Poly(Urethane-Imide)s and Their Properties. Journal of Polymer Science Part A: Polymer Chemistry, 35, 3745-3753.

https://doi.org/10.1002/(SICI)1099-0518(199712)35:17<3745::AID-POLA14>3.0.C O;2-D 
[3] Zuo, M., Xiang, Q. and Takeichi, T. (1998) Preparation and Properties of Novel Poly(Urethane-Imide)s. Polymer, 39, 6883-6889. https://doi.org/10.1016/S0032-3861(98)00179-7

[4] Asai, K., Onouchi, Y., Inoue, S. and Okamoto, H. (1998) First Evidence of Polyimide Elasto-Mer Prepared from Polyurea and Pyromellitic Dianhydride. Chemistry Letters, 3, 227-228. https://doi.org/10.1246/cl.1998.227

[5] Zuo, M. and Takeichi, T. (1999) Preparation and Characterization of Poly(UrethaneImide) Films Prepared from Reactive Polyimide and Polyurethane Prepolymer. Polymer, 40, 5135-5160. https://doi.org/10.1016/S0032-3861(98)00726-5

[6] Takeichi, T., Yamazaki, Y., Ito, A. and Zuo, M. (1999) Preparation and Properties of Porous Polyimide Films Prepared by the Pyrolysis of Poly(Urethane-Imide) Films. Journal of Photopolymer Science and Technology, 12, 203.

[7] Philip Gnanarajian, T., PadmanabhaIyer, N., Sultan Nasar, A. and Radhakrishnan, G. (2002) Preparation and Properties of Poly(Urethane-Imide)s Derived from Amine-Blocked-Polyuret-Hane Prepolymer and Pyromellitic Dianhydride. European Polymer Journal, 38, 487-495. https://doi.org/10.1016/S0014-3057(01)00216-6

[8] Asai, K., Inoue, S. and Okamoto, H. (2000) Preparation and Properties of ImideContaining Elastic Polymers from Elastic Polyureas and Pyromellitic Dianhydride. Journal of Polymer Science Part A: Polymer Chemistry, 38, 715-723. https://doi.org/10.1002/(SICI)1099-0518(20000215)38:4<715::AID-POLA6>3.0.CO; $\underline{2-8}$

[9] Takeichi, T., Yamazaki, Y., Fukui, T., Matsumoto, A. and Inagaki, M. (2000) Preparation and Characterization of Porous Carbonized Films by the Pyrolysis of Poly (Urethane-Imide) Films. Tanso, 195, 388.

[10] Takeichi, T. and Arimatsu, K. (2001) Preparation and Properties of Poly(UrethaneImide) Films from Polyether Polyol: An Attempt to Nanoporous Polyimide Films. Journal of Photopolymer Science and Technology, 14, 67.

[11] Liu, J. and Ma, D. (2002) Study on Synthesis and Thermal Properties of Polyurethane-Imide Copolymers with Multiple Hard Segments. Journal of Applied Polymer Science, 84, 2206-2215. https://doi.org/10.1002/app.10421

[12] Takeichi, T., Ujiie, K. and Inoue, K. (2005) High Performance Poly(Urethane-Imide) Prepared by Introducing Imide Blocks into the Polyurethane Backbone. Polymer, 46, 11225-11231. https://doi.org/10.1016/j.polymer.2005.09.075

[13] Qiu, F., Yang, D. and Li, P. (2009) Synthesis, Characterization, and Thermo-Optical Properties of Poly(Urethane-Imide) Based on Azo-Disperse Dye on Its Side Chains. Iranian Polymer Journal, 18, 651.

[14] Kogiso, T. and Inoue, S. (2010) Synthesis and Properties of Elastic PolyurethaneImide. Journal of Applied Polymer Science, 115, 242-248.

https://doi.org/10.1002/app.31126

[15] Ueda, T., Nishio, T. and Inoue, S. (2017) Influences of Diamines on the Morphologies and the Chemical, Thermal, and Mechanical Properties of Polyurethane-Imide Elastomers. Open Journal of Organic Polymer Materials, 7, 47-60. https://doi.org/10.4236/ojopm.2017.74004

[16] Salary, J. and Smith, C.H. (1975) Polyurethane/Imide Modified Foam. Journal of Cellular Plastics, 11, 262. https://doi.org/10.1177/0021955X7501100505

[17] Sang, X., Wang, R., Chen, X., Zhang, L., An, M. and Shen, L. (2012) Structure and Compression Properties of Polyurethane-Imide Foams. Applied Mechanics and Materials, 117. 
[18] Muller-Cristadoro, A. and Prissok, F. (2014) Method for Production of Polymer Foams Comprising Imide Groups. U.S. Pat. Appl. Publ, US 20140042356 A1.

[19] Yeganeh, H., Barikani, M. and NoeiKhodabadi, F. (2000) Synthesis and Properties of Novel Thermoplastic Poly(Urethane-Imide)s. European Polymer Journal, 36, 2207-2211. https://doi.org/10.1016/S0014-3057(99)00284-0

[20] Li, Z., Xu, T., Sun, J., Zhang, F., Sun, B. and Wang, Z. (2008) Preparation and Properties of Polyurethaneurea-Imide Elastomer. Hecheng Xiangjiao Gongye, 31, 312.

[21] Xu, T., Yan, W., Wang, S.-J., Li, Z.-F., Sun, B.-Q. and Wang, M.-X. (2008) Synthesis of Polyurethane Modified Bismaleimide (UBMI) and Polyurethane-Imide Elastomer. Chinese Journal of Polymer Science, 26, 117. https://doi.org/10.1142/S0256767908002741

[22] Mifune, Y., Nishio, T., Shibata, J. and Ueda, Y. (2010) Jpn. Kokai Tokyo koho JP 201022567.

[23] Song, J., Chen, G., Wu, G., Cai, C., Liu, P. and Li, Q. (2011) Thermal and Dynamic Mechanical Properties of Epoxy Resin/Poly(Urethane-Imide)/Polyhedral Oligomeric Silsesquioxane Nanocomposites. Polymer for Advanced Technologies, 22, 2069 2074. https://doi.org/10.1002/pat.1722

[24] Gui, D., Gao, X., Hao, J. and Liu, J. (2014) Preparation and Characterization of Liquid Crystalline Polyurethane-Imide Modified Epoxy Resin Composites. Polymer Engineering \& Science, 54, 1704-1711. https://doi.org/10.1002/pen.23712 